ORIGINAL ARTICLE

\title{
Pharmaceutical Regulatory Framework in Ethiopia: A Critical Evaluation of Its Legal Basis and Implementation
}

\author{
Sultan Suleman ${ }^{1,2}$, Abdulkadir Woliyi ${ }^{3}$, Kifle Woldemichael ${ }^{4}$, Kora Tushune, \\ Luc Duchateau', Agnes Degroote ${ }^{2}$, Roy Vancauwenberghe ${ }^{7 \#}$, Nathalie Bracke ${ }^{2}$, \\ Bart De Spiegeleer ${ }^{2}$
}

ABSTRACT

BACKGROUND: Effective and enforceable national regulations describing the manufacture and (re)packaging, export and import, distribution and storage, supply and sale, information and pharmacovigilance of medicines are required to consistently ensure optimal patient benefit. Expansion of pharmaceutical industries in many countries with advancement in transport technologies facilitated not only trade of genuine pharmaceutical products but also the circulation of poor quality medicines across the globe. In Ethiopia, even though "The Pharmacists and Druggists Proclamation No 43/1942" was used to regulate both the professions and the facilities where they were practiced, comprehensive regulation of the pharmaceutical market was introduced in 1964 by a regulation called "Pharmacy Regulation No. 288/ 1964". This legislation formed the legal basis for official establishment of drug regulation in the history of Ethiopia, enabling the regulation of the practice of pharmacists, druggists and pharmacy technicians; manufacturing, distribution, and sale of medicines. In June 1999, a new regulation called the "Drug Administration and Control Proclamation No. 176/1999" repealed most parts of the regulation 288/1964. The law established an independent Drug Administration and Control Authority (DACA) with further mandate of setting standards of competence for licensing institutions/facilities. DACA was re-structured as Food, Medicine and Health Care Administration and Control Authority (EFMHACA) of Ethiopia by the "Proclamation No. 661/2009" in 2010 bearing additional responsibilities like regulation of food, health care personnel and settings. The mere existence of this legal framework does not guarantee complete absence of illegal, substandard and falsified products as well as illegal establishments in the pharmaceutical chain. Therefore, the objective of the research is to assess the pharmaceutical regulatory system in Ethiopia and to reveal possible reasons for deficiencies in the pharmaceutical chain.

METHODS: An archival review, an in-depth interview of key informants and an institutions-based cross-sectional survey study were conducted during March to April 2013. The comprehensiveness of the pharmaceutical law to protect public health relative to three selected African countries (South Africa, Tanzania and Uganda) and European Union, and implementation was assessed.

RESULTS: The study revealed that Ethiopia does have a written national drug policy upon which the Medicines Regulatory Proclamation 661/2009 is based. According to this proclamation, the Ethiopian The Food, Medicines and Healthcare Administration and Control Authority is mandated to execute the regulatory activities as per the council of ministers regulation 189/2010. The legal framework for

\footnotetext{
${ }^{1}$ School of Pharmacy, Jimma University, Jimma, Ethiopia

${ }^{2}$ Drug Quality and Registration (DruQuaR) Group, Faculty of Pharmaceutical Sciences, Ghent University, Ghent, Belgium

${ }^{3}$ Food, Medicine and Healthcare Administration and Control Authority (FMHACA), Addis Ababa, Ethiopia

${ }^{4}$ Department of Epidemiology, College of Health Sciences, Jimma University, Jimma, Ethiopia

${ }^{5}$ Department of Health Service Management, College of Health Sciences, Jimma University, Jimma, Ethiopia

${ }^{6}$ Department of Physiology and Biometrics, Faculty of Veterinary Medicine, Ghent University, Merelbeke, Belgium

${ }^{7}$ Federal Agency for Medicines and Health Products, Brussels, Belgium

Corresponding Author: Sultan Suleman ${ }^{1}$, Email: sultan.suleman@ju.edu.et

\#Deceased and this manuscript is a tribute to him
} 
pharmaceutical regulation of Ethiopia was founded to fulfill all the medicines regulatory functions potentially enabling to combat illegal, substandard and falsified medicines and illegal establishments. Moreover, all the key informants witnessed that the government is commited and proclamation 661/2009 is comprehensive, but they stressed the compelling need of regulatory tools for effective implementation. From the institution-based cross-sectional study, it was revealed that there exist illegal sources formedicine in the pharmaceutical market. The main reasons for their existence were regulatory factors including weak regulatory enforcement (64.5\%), lack of informal market control (60.8\%), weak port control (50.0\%), and poor cooperation between executive bodies (39.6\%); and resource constraint (27.8\%), which is an institutional factor.

CONCLUSIONS: From legislative point of view, the medicines regulatory framework in Ethiopia fulfils all regulatory functions required for effective medicines regulation. However, the existence of the legislation by its own is not a guarantee to prevent the existence of unauthorized/illegal medicine sources since this requires effective implementation of the legislation, which is in fact affected by the governments political commitment, resource and intergovernmental cooperation.

KEYWORDS: Drug policy, Pharmaceutical legislation, Medicines regulation, Illicit/unregistered/substandard/falsified medicines and sources, Ethiopia

DOI: http://dx.doi.org/10.4314/ejhs.v26i3.9

\section{INTRODUCTION}

The fundamental purpose of medicine regulation is to protect public health and to ensure that medicines on national markets and in international commerce are safe, effective and of good quality, and used in accordance with good practices. Medicines are important aspects of public health and must be available and accessible to the public. To improve access to medicines, good governance is crucial and contributes to health systems strengthening. Good governance in the pharmaceutical sector refers to the formulation and implementation of appropriate policies and procedures that ensure the effective, efficient and ethical management of medicine regulation, in a manner that is transparent, accountable and follows the rule of law (1-4).

Since the mid-1930s, many new pharmaceutical products have flourished and trade in the pharmaceutical industry has taken on international dimensions. However, the circulation of toxic, substandard and counterfeit drugs on the national and international market has increased. This is mainly due to ineffective regulation of production and trade in pharmaceutical products in both exporting and importing countries. The use of these poor quality medicines may also threaten the health and lives of patients (5). WHO estimates that from one million deaths that occur from malaria annually, 200,000 would be avoidable if the medicines available were effective, of good quality and used correctly. A study conducted in
Southeast Asia in 2001 revealed that $38 \%$ of 104 anti-malarial drugs on sale in pharmacies did not contain any active ingredient and resulted in a number of preventable deaths (6). Moreover, inefficiencies in medicines regulatory system can delay entry of needed medicines in a market; hence, a barrier to access for users and to the profits and growth of the pharmaceutical business (7).

According to $\mathrm{WHO}$, about $20 \%$ of countries have well-developed and operational medicines regulation. Of the rest, approximately half have regulation of varying capacity and level of development, and $30 \%$ have either no or very limited medicines regulation; revealing that many low-income countries cannot ensure safety, efficacy and quality of medicines circulating on their markets. The problems of ineffective regulation have global implications (8) and minimum requirements for effective medicines regulation should exist in any country to counter poor quality medicines (9).

The situation is severe in sub-Saharan African countries where there are limited resources and pharmaceutical manufacturing capacity with a high disease burden. Thus, parallel, unregulated medicines markets are posing serious risks for individual and public health (10). As far as Ethiopia is concerned, there is no comprehensive evaluation of the basic medicines regulatory framework and associated unregulated medicines and their sources. 
Ethiopia is one of the sub-Saharan African countries where the pharmaceutical sector is being guided by a national medicine policy (11). "The Pharmacists and Druggists Proclamation No 43/1942" was the basis for pharmaceutical regulation where both pharmacists and druggists together with the facilities where they practiced were regulated. Comprehensive regulation of the pharmaceutical sector was started in the early stages by a regulation called "Pharmacy Regulation No. 288/ 1964", which formed the legal basis for official establishment of drug regulation in the history of Ethiopia. The Pharmacy and Laboratory Department under the then Ministry of Health was responsible for medicines regulation until June 1999 when a new regulation called the "Drug Administration and Control Proclamation No. 176/1999" was promulgated on 29 June 1999. Following this proclamation, the regulatory component of the Pharmacy Department was transformed to an independent Drug Administration and Control Authority (DACA) of Ethiopia in September 2001 (12). DACA was re-structured as Food, Medicine and Health Care Administration and Control Authority (EFMHACA) of Ethiopia by "Proclamation No. 661/2009" in 2010 bearing additional responsibilities like regulation of food, health care personnel and settings (13).

The rapid growth and development of pharmaceutical sector after the downfall of the Dergue regime in Ethiopia has led to the majority of pharmaceuticals and medical supplies being provided by both the public and private sectors. Currently, there are 32 plants (small and large scale) involved in the manufacturing of pharmaceuticals and related products of which only 12 are manufacturers of generic finished pharmaceutical dosage forms. The remaining are involved in the small scale manufacturing of medical devices, supplies, laboratory reagents, cosmetics, and disinfectants (14). According to EFMHACA website (www.efmhaca.gov.et), there are 133 importers, 272 wholesalers, 377 pharmacies, 1699 drug shops and 1392 rural drug venders currently existing in Ethiopia.

Some primary data sources reveal that poor quality pharmaceutical products are in the market because of in-efficiencies in pharmaceutical regulatory functions in Ethiopia (15). In the past few years, more than $60 \%$ of foreign manufacturers have failed to comply with GMP and hence marketing authorization (16). In the area of post-registration testing, low income countries tended to collect fewer samples and report higher rates of products failing testing (17). For example, the result of trend analysis on the quality control laboratory tests carried out in Ethiopia for samples submitted from the year 2007-2011 shows that most failures of samples submitted for post-marketing surveillance (PMS) was higher $(9.5 \%-15.5 \%)$ than samples submitted for the purpose of marketing authorization $(4.7 \%$ $10.7 \%$ ) (16). Such public health problems should thus be investigated through critical evaluation of the legal basis and implementation of the pharmaceutical regulatory framework in Ethiopia.

Regular regulatory systems assessment is important for the policy makers in designing or updating policies and strategies to prevent public health from medicines whose safety, efficacy and quality are not ensured and authorized to circulate in the market. The legal basis of the existing pharmaceutical regulatory system in Ethiopia was critically reviewed in comparison with relatively good regulatory systems of three African countries (South Africa, Tanzania and Uganda) and the current EU regulatory system. The comprehensiveness of the legislation to protect the public health was critically evaluated and its practical implementation was assessed through institution-based cross-sectional survey.

\section{METHODS AND MATERIALS}

The study was conducted to critically assess the legal framework of the pharmaceutical regulatory system based on Proclamation No.661/2009 and its implementation status on the institutions regulated under the national medicine regulatory authority of Ethiopia. An archival review, in-depth interviews (with key informants selected from institutions involved in the pharmaceutical sector) and institution-based cross-sectional survey using semi-structured questionnaires developed based on WHO guideline were used to gather data $(18,19)$. A critical review on the drug regulation was undertaken followed by semi-structured interviews with key informants from academia, industry and EFMHACA to supplement information gathered from the legal sources. 
For the review process, archival review guide was used as a data collection tool. The tool was developed based on WHO guideline (20) and contains detail description on the general content of the medicine legislation and a checklist for the functions of the medicine regulatory authority as evaluation points. The basic purpose for record/archival review was to assess the comprehensiveness of the legal framework to protect public health in comparison to medicine regulatory authorities (MRAs) of three selected African countries (South Africa, Tanzania and Uganda) and EU's European Medicines Agency (EMA). According to a study conducted by WHO in 2006, South Africa had a "fully functional" MRA, where as Uganda had a "functional" MRA. The study further reported that the MRA of Tanzania and Ethiopia had "potential for effective regulation" (21). Therefore, the selection of the three African countries was based on this literature while EU was selected for its strict medicine regulatory system.

The review process further assessed the availability of basic resources to implement the medicines law in relation to marketing authorization/regulatory approvals and regulatory inspections/enforcement in Ethiopia. Overall, records on legal framework, resource for implementation and implementation reports in protecting public health were assessed. Financial and human resource documents, registry for regulatory approval/marketing authorization of medicines, breaches of the law related to unauthorized medicines and their sources, and the associated regulatory measures taken on violations in comparison to penalties provided in the legislation and guidelines were the other focus areas in the record review. Moreover, references on quality of products from the national market were included.

The purpose of in-depth interview was to get details and new insights from the right sources. A total of 12 key informants selected from different institutions in Ethiopia (EFMHACA, custom authority, Ethiopian pharmaceutical association, Ethiopian druggist association, Ethiopian pharmaceuticals manufacturers association and academia) were interviewed. In-depth interviews were conducted with individuals selected based on their involvement in the regulatory system, and/or role as a representative of an industry or stakeholder group. Interviewees were based within different institutions and from various disciplines: pharmacy, law, chemistry, food technology and management. Several of the individuals interviewed were expert participants with work experience of more than 20 years while the minimum work experience was 10 years. Points of interview included: (1) the problems related to safety, efficacy and quality pharmaceuticals in the market; (2) government's political commitment at different levels; (3) adequacy and comprehensiveness of the current legal provision in addressing all the pharmaceutical regulatory activities; (4) the capacity and organization of the regulatory system at various levels in terms of resources and regulatory infrastructures; (5) cooperation and collaboration between these medicine regulatory bodies at different level and their collaboration with other law enforcing agencies such as customs, police and judiciary bodies; and (6) the public support for medicine regulation particularly in reporting illegal medicines circulation.

Institutional-based cross-sectional survey was conducted to assess the implementation of those regulatory functions described in the legislation. Semi-structured questionnaire developed based on WHO guideline containing personal information, details of general information on medicines regulation, and unauthorized sources and/or products if any was used to collect data. The institutions-based crosssectional study was conducted during March to April 2013 to assess the existing regulatory system and its implementation status in Ethiopia. The source population consisted of all pharmacy professionals working in EFMHACA and institutions regulated by EFMHACA. Selected pharmacy professionals from EFMHACA with work experience of two years and above as well as technical managers and marketing personnel of the regulated institutions were included in the study.

There were 346 institutions regulated by EFMHACA, from which a sampling frame of $30 \%$ ( $n=105)$ was randomly selected for the study. From each of the 105 institutions, two study participants were purposively selected. Out of a total of 84 pharmacy professionals in EFMHACA, 52 participants were included. One hundred and ninety-seven technical and marketing managers 
participated in the study, making the total number 249.

Quantitative data were edited, coded, and analyzed using SPSS Statistics version 16.0 software. Descriptive analyses were conducted and outputs were presented using frequency tables and charts. The data obtained from key informants' interview were summarized, analyzed and presented in a descriptive way per thematic area. Similarly, summaries were made from the archival review findings on the critical features of medicine regulation. A multivariable logistic regression was used to investigate the relationship between the different reported factors for the existence of illegal pharmaceutical business.

\section{RESULTS}

\section{The legal basis of pharmaceutical regulation in Ethiopia: archival review}

Legal framework: An overview of medicines regulatory framework in Ethiopia, Tanzania, Uganda, South Africa, and EU is presented in Table 1, while the legal framework of the respective medicine regulatory authorities is presented in Table 2. For all the countries, there exists a well-defined law for medicine regulation with clearly articulated objectives of protecting public health from unsafe, inefficacious and poor quality medicines. The medicine legislation of Ethiopia is based on proclamation 661/2009 with the objective of safeguarding and protecting the public health through ensuring that all medicines (produced locally or imported) that circulate in the market and used in the country are safe, effective and consistently meet the acceptable quality standards.

In Ethiopia, the Parliament approves proclamations, while regulations are approved by Council of Ministers similar to that of Tanzania, Uganda and South Africa. In EU, legislations and directives are all approved jointly by the European Parliament and the Council of EU.

Governing body: A good medicines law creates administrative governing bodies to put rules in to practice (22). In all the studied countries (Ethiopia, South Africa, Tanzania, Uganda and EU), medicine legislations ensure legal provisions for the establishment of a governing body called MRA responsible for enforcing the legislation. EFMHACA is empowered by the Council of Ministers Legislation 189/2010 as the governing body for medicine regulation in Ethiopia with its organizational structure presented in Figure 1. Food and Drugs Administration (TFDA), National Drug Authority (NDA) and Medicine Control Council (MCC) in Tanzanian are the executive organs to enforce medicines law in Tanzania, Uganda and South Africa, respectively. The European Medicines Agency (EMA) is responsible for enforcing medicines law in EU.

The overall responsibility and accountability for all aspects of medicine regulation is given to a single agency in Tanzania, Uganda, South Africa and EU, while it is distributed horizontally between EFMHACA and the Ministry of Agriculture and Rural Development, and vertically between EFMHACA and regional state regulatory bodies (RRBs) in the case of Ethiopia. The Ministry of Agriculture and Rural Development is responsible to regulate veterinary medicinal products, whereas RRBs are responsible to regulate establishments in the distribution chain except importers and wholesalers.

\section{Regulatory provisions to MRAs}

The content and domains of regulations of Ethiopia, Tanzania, Uganda, South Africa and EU is presented in Table 3. In terms of its content and domain of regulation, Poclamation 661/2009 of Ethiopia covers most of the critical features for medicine regulation with provisions for the major regulatory processes. Pharmaceuticals are subject to numerous controls at all levels, and EFMHACA is granted to regulate their manufacture, distribution, marketing, prescription, labeling and dispensing. However, there were some differences between legal provisions in Ethiopia and the other countries whose legislations were reviewed for comparison. The variations lie on the domains of regulation like scope of regulated products (e.g. veterinary medicines are excluded from EFMHACA), price control and overall responsibility distribution for medicines regulation. 
Table 1: An overview of the medicine regulatory framework in the selected countries

\begin{tabular}{|c|c|c|c|c|c|c|c|}
\hline$\#$ & \multicolumn{2}{|l|}{ Features } & Ethiopia & Tanzania & Uganda & South Africa & EU \\
\hline 1 & \multicolumn{2}{|c|}{$\begin{array}{l}\text { Current medicine law of the } \\
\text { country }\end{array}$} & $\begin{array}{l}\text { Food, Medicine } \\
\text { and Health care } \\
\text { Administration } \\
\text { and control } \\
\text { proclamation } \\
\text { No.661/2009 }\end{array}$ & $\begin{array}{l}\text { Tanzanian Food, } \\
\text { Drugs and } \\
\text { cosmetics Act No. I } \\
\text { of } 2003\end{array}$ & $\begin{array}{l}\text { The national drug policy and } \\
\text { authority act establish a } \\
\text { national drug policy and a } \\
\text { national drug authority. } \\
\text { Chapter } 206 \text { of the law of } \\
\text { UgandaCommenced: } 3 \\
\text { December, } 1993\end{array}$ & $\begin{array}{l}\text { Medicine and } \\
\text { Related substances } \\
\text { Act } 101 \text { of } 1965 \text { as } \\
\text { amended act } 59 \text { of } \\
2002 \text { of South } \\
\text { Africa }\end{array}$ & $\begin{array}{l}\text { European Medicines } \\
\text { Agency (EMA) } \\
\text { (Regulation (EC) No. } \\
726 / 2004 \text { ) }\end{array}$ \\
\hline 2 & \multicolumn{2}{|c|}{$\begin{array}{l}\text { Objectives of the current } \\
\text { law/proclamation/regulation }\end{array}$} & $\begin{array}{l}\text { Protect public } \\
\text { health from } \\
\text { unsafe, } \\
\text { inefficacious } \\
\text { and poor quality } \\
\text { medicine }\end{array}$ & $\begin{array}{l}\text { To ensure that only } \\
\text { safe, quality and } \\
\text { efficacious } \\
\text { products are } \\
\text { approved for use in } \\
\text { the country. }\end{array}$ & $\begin{array}{l}\text { To ensure the availability at all } \\
\text { times of essential, efficacious } \\
\text { and cost-effective drugs to the } \\
\text { entire population of Uganda }\end{array}$ & $\begin{array}{l}\text { To provide for the } \\
\text { registration of } \\
\text { medicines and } \\
\text { related substances } \\
\text { intended for human } \\
\text { and animal use }\end{array}$ & $\begin{array}{l}\text { Protection of public } \\
\text { health on the basis of } \\
\text { scientific criteria of } \\
\text { quality, safety and } \\
\text { efficacy of medicinal } \\
\text { products concerned. }\end{array}$ \\
\hline \multirow[t]{4}{*}{3} & \multirow[t]{4}{*}{$\begin{array}{l}\text { Provision/Ap } \\
\text { provals }\end{array}$} & $\begin{array}{l}\text { Proclamation/A } \\
\text { ct }\end{array}$ & Parliament & Parliament & Parliament & Parliament & \multirow{2}{*}{$\begin{array}{l}\text { European } \\
\text { parliament/the council } \\
\text { of EU }\end{array}$} \\
\hline & & $\begin{array}{l}\text { Regulations/ } \\
\text { Directives }\end{array}$ & $\begin{array}{l}\text { Council of } \\
\text { Ministers }\end{array}$ & $\begin{array}{l}\text { Ministry upon } \\
\text { advise of TFDA }\end{array}$ & Ministry upon advise of NDA & $\begin{array}{l}\text { Department of } \\
\text { Health }\end{array}$ & \\
\hline & & Guidelines & EFMHACA & TFDA & NDA & $\mathrm{MCC}$ & EMA \\
\hline & & $\begin{array}{l}\text { Official } \\
\text { Journal }\end{array}$ & Negarit Gazette & Gazette & Gazette & Gazette & $\begin{array}{l}\text { Official Journal for EU } \\
\text { L } 136\end{array}$ \\
\hline 4 & \multicolumn{2}{|c|}{$\begin{array}{l}\text { Executive organ to enforce the } \\
\text { law }\end{array}$} & $\begin{array}{l}\text { EFMHACA and } \\
\text { RRBs }\end{array}$ & TFDA & NDA & $\mathrm{MCC}$ & $\begin{array}{l}\text { EMA, EDQM, } \\
\text { national competent } \\
\text { authorities }\end{array}$ \\
\hline
\end{tabular}

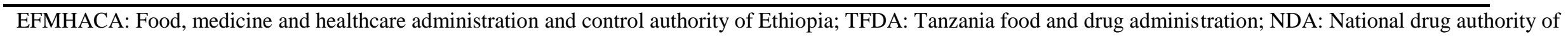
Uganda; MCC: Medicine control council of South Africa 
Table 2: The legal framework of the medicine regulatory authorities (MRAs)

\begin{tabular}{|c|c|c|c|c|c|}
\hline & Ethiopia & Tanzania & Uganda & South Africa & $\overline{E U}$ \\
\hline $\begin{array}{l}\text { Legal status of the } \\
\text { regulatory authority }\end{array}$ & $\overline{\mathrm{A}}$ & $\overline{\mathrm{A}}$ & $\bar{A}$ & $\bar{B}$ & $\bar{A}$ \\
\hline $\begin{array}{l}\text { Main regulatory } \\
\text { authority }\end{array}$ & EFMHACA & TFDA & NDA & MCC & EMA \\
\hline Supervisory body & $\mathrm{MOH}$ and RHB & $\mathrm{MOH}$ & $\mathrm{MOH}$ & $\mathrm{MOH}$ & $\mathrm{MOH}$ \\
\hline $\begin{array}{l}\text { Links with other local } \\
\text { regulatory agency }\end{array}$ & MOARD \& RRB & NA & NA & NA & $\begin{array}{l}\text { Member } \\
\text { states }\end{array}$ \\
\hline Line of command & Multiple agencies & $\begin{array}{l}\text { Single } \\
\text { agency }\end{array}$ & $\begin{array}{l}\text { Single } \\
\text { agency }\end{array}$ & Single agency & $\begin{array}{l}\text { Single } \\
\text { agency }\end{array}$ \\
\hline $\begin{array}{l}\text { Power to hire or fire } \\
\text { personnel }\end{array}$ & Yes* & Yes & Yes & Yes & Yes \\
\hline Financial independence & Yes & Yes & Yes & Yes & Yes \\
\hline
\end{tabular}

$\mathrm{A}=$ semi-autonomous statutory authority under Ministry of Health $(\mathrm{MOH}), \mathrm{B}=$ council under MOH, NA = not applicable, RHB $=$ Regional states Health Bureau, * available at federal level

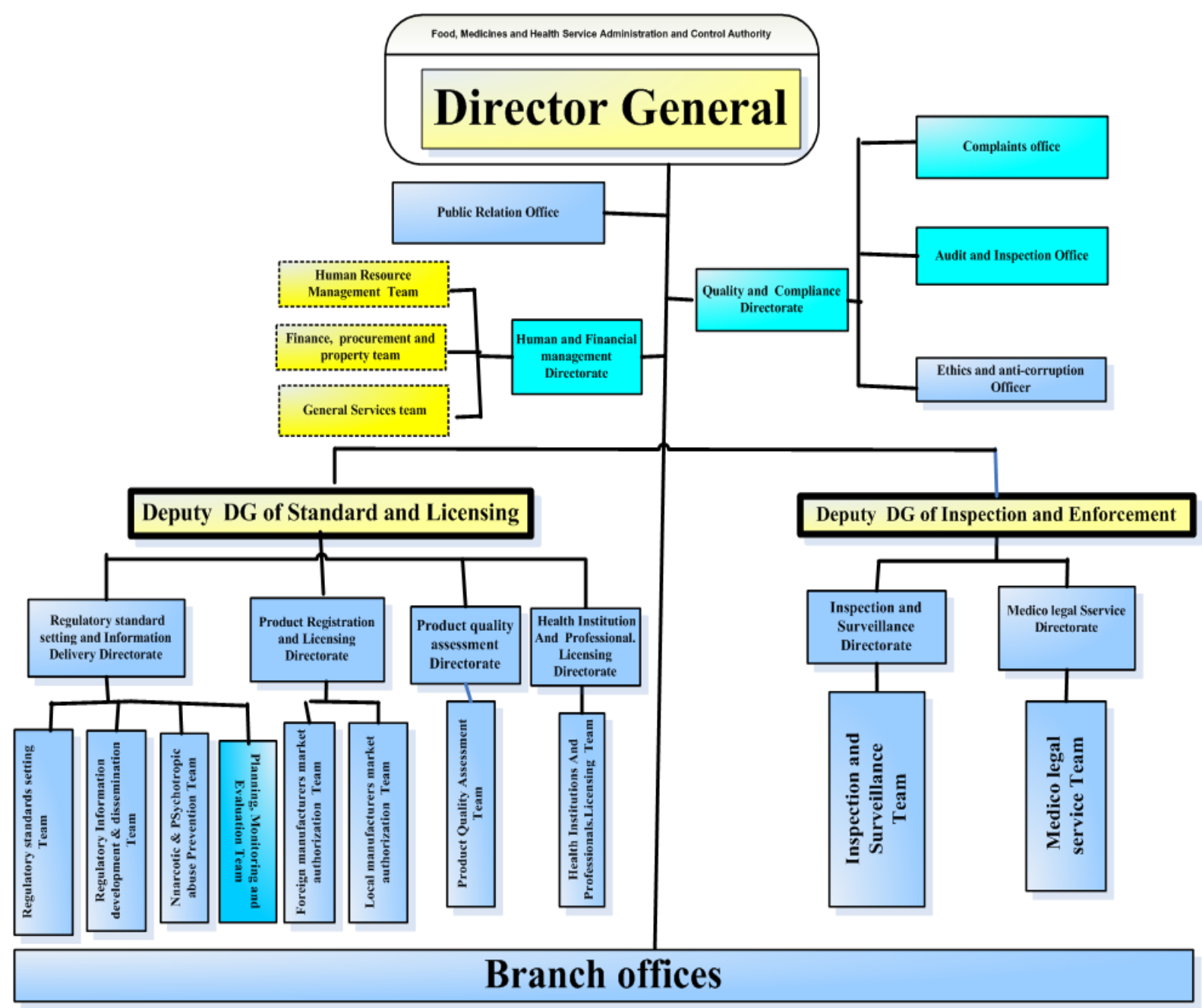

Figure 1: Organizational structure of Food, Medicine and Health care Administration and Control Authority of Ethiopia 
Table 3: Content of medicine laws and some regulatory activities of Ethiopia, the three African countries and EU

\begin{tabular}{|c|c|c|c|c|c|c|c|}
\hline$\#$ & Content of the law & & Ethiopia & Tanzania & Uganda & South Africa & $\overline{E U}$ \\
\hline \multirow[t]{12}{*}{1} & Product classification & Human medicine & $\bullet$ & $\bullet$ & $\bullet$ & $\bullet$ & $\bullet$ \\
\hline & & Veterinary medicine & $\circ$ & $\bullet$ & $\bullet$ & $\bullet$ & $\bullet$ \\
\hline & & Medical devices & - & • & $\bullet$ & - & - \\
\hline & & Blood \& blood products & $\bullet$ & • & $\bullet$ & $\bullet$ & $\bullet$ \\
\hline & & Tissue transplant & $\bullet$ & $\bullet$ & $\bullet$ & $\bullet$ & $\bullet$ \\
\hline & & Cosmetics & - & $\bullet$ & • & - & - \\
\hline & & Narcotics \& psychotropic & $\bullet$ & • & $\bullet$ & $\bullet$ & $\bullet$ \\
\hline & & Herbal products & $\bullet$ & $\bullet$ & $\bullet$ & - & $\bullet$ \\
\hline & & Functional foods & • & • & • & • & $\bullet$ \\
\hline & & Food and additives & $\bullet$ & $\bullet$ & $\bullet$ & $\bullet$ & $\bullet$ \\
\hline & & ATMP & $\circ$ & $\circ$ & $\circ$ & $\circ$ & - \\
\hline & & Border-line products & o & ० & ○ & $\circ$ & $\bullet$ \\
\hline \multirow[t]{25}{*}{2} & Regulatory functions & & & & & & \\
\hline & 2.1. Product assessment and registration & Human medicine & • & • & • & - & - \\
\hline & & Veterinary medicine & $\square$ & • & $\bullet$ & $\bullet$ & $\bullet$ \\
\hline & & Herbal products & $\bullet$ & • & • & - & - \\
\hline & & Biological products & - & • & • & • & - \\
\hline & & Cosmetics & $\bullet$ & $\bullet$ & $\bullet$ & $\bullet$ & $\bullet$ \\
\hline & & Foods and additives & $\bullet$ & • & $\bullet$ & - & - \\
\hline & 2.2. Premise licensing & Manufacture & - & • & • & - & • \\
\hline & & Importers /wholesalers & $\bullet$ & $\bullet$ & $\bullet$ & $\bullet$ & $\bullet$ \\
\hline & & Retail outlets & $\circ$ & - & - & - & - \\
\hline & 2.3. Inspections & GMP inspection & $\bullet$ & $\bullet$ & $\bullet$ & $\bullet$ & $\bullet$ \\
\hline & & Supply chain inspection & $\circ^{\mathrm{a}}$ & • & • & - & - \\
\hline & 2.4. Quality control & & $\bullet$ & • & • & - & - \\
\hline & 2.5. Pharmacovigilance & & $\bullet$ & $\bullet$ & • & $\bullet$ & $\bullet$ \\
\hline & 2.6. Control of product promotion & & $\bullet$ & $\bullet$ & $\bullet$ & $\bullet$ & $\bullet$ \\
\hline & 2.7. Clinical trial control & & - & • & • & - & - \\
\hline & 2.8. Import/export control & & • & • & • & $\bullet$ & $\bullet$ \\
\hline & 2.9. Price control & & $\circ$ & • & • & $\bullet$ & $\bullet$ \\
\hline & 2.10. Sources of products regulated & Private manufacture & $\bullet$ & • & • & - & $\bullet$ \\
\hline & & Government manufacture & $\bullet$ & $\bullet$ & $\bullet$ & - & $\bullet$ \\
\hline & & Private import & $\bullet$ & $\bullet$ & $\bullet$ & - & - \\
\hline & & Government import & - & • & • & - & - \\
\hline & 2.11. Control of raw materials & Active pharmaceutical ingredient & $\bullet$ & $\bullet$ & • & $\bullet$ & $\bullet$ \\
\hline & & Excipients & - & • & • & $\bullet$ & $\bullet$ \\
\hline & 2.12. Registration harmonization & & $\circ$ & EAC and SADC & EAC & EAC and SADC & $\mathrm{ICH}$ \\
\hline
\end{tabular}

ATMP: Advanced therapy medicinal products; Border-line products: between medicinal products and food supplements, biocides, cosmetic products or medical devices.


importer/wholesalers, lower supply chains are regulated by regional state regulatory bodies in Ethiopia 
Product classification: Pharmaceutical legislations provide product classifications based on definitions for medicines or medicinal products. Product classification is important for executing pharmaceutical laws governing production, marketing and utilizations of medicines.

According to Article 1 of Directive 2001/83/EC of EU, a medicinal product is defined as: (a) any substance or combination of substances presented as having properties for treating or preventing disease in human beings/animals; and/or (b) any substance or combination of substances which may be used in, or administered to, human beings, either with a view to restoring, correcting or modifying physiological functions by exerting a pharmacological, immunological or metabolic action, or to making a medical diagnosis. Moreover, Article 2(2) of the Directive provides classification of a product into a medicinal product, where doubt remains as to its classification as a medicine or another type of product; but the European Court of Justice judgment is helpful. Product classification in EU considers presentation and/or purpose/function aspects of the products.

Article 2(6) of Proclamation No. 661/2009 of Ethiopia defines medicine as any substance or mixture of substances used in the diagnosis, treatment, mitigation or prevention of a disease in human. It includes narcotic drugs, psychotropic substances and precursor chemicals, traditional medicines, complementary or alternative medicine; poisons, blood and blood products, vaccine, radioactive pharmaceuticals, cosmetics and sanitary items and medical instruments.

Product classification in Ethiopia (and the three African countries) addresses only the functional issue of products and neglects the presentation aspects, which are well described in EU. It poses greater challenges to classifying products that are on the borderline between medicinal products and food supplements, biocides, cosmetic products and medical devices. Moreover, advanced therapy medicinal products (ATMP) like gene therapy, somatic cell therapy and tissue engineering are not classified in Ethiopia, Tanzania, Uganda and South Africa. Therefore, EU's product classification is much broader and provides a wider scope of products to be regulated under the law.

\section{Product assessment and registration}

Medicines registration, also called marketing authorization, is often a major element in national pharmaceutical law. It is carried out by MRAs to ensure that a medicinal product has been adequately tested and evaluated for safety, efficacy and quality; and the product information provided by the manufacturer is accurate.

The comparative presentation of market authorization by EFMHACA, TFDA, NDA, MCC and EMA is given in Table 4. All the MRAs have a legal basis for marketing authorization of the pharmaceutical products with guidance for applicants and standard operating procedures for assessors. Except EFMHACA, all the MRAs make use of external experts in the form of various committees and are involved in regional or international harmonization of registration process. EFMHACA has a single advisory committee, and is not currently participating in regional harmonization for registration, even though Ethiopia is very recently working towards harmonization of quality assurance for pharmaceutical and medical products with Intergovernmental Authority on Development (IGAD) member countries. 
Table 4: Marketing Authorization process in five regulatory authorities

\begin{tabular}{|c|c|c|c|c|c|}
\hline \multirow[t]{2}{*}{ Particulars } & \multicolumn{3}{|c|}{ Countries } & \multirow[b]{2}{*}{$\begin{array}{l}\text { South } \\
\text { Africa }\end{array}$} & \multirow[b]{2}{*}{$E U$} \\
\hline & Ethiopia & Tanzania & Uganda & & \\
\hline Legal basis for authorization & - & - & - & - & - \\
\hline Guidance for applicants & - & - & - & - & • \\
\hline SOP for assessment & - & • & - & - & - \\
\hline Advisory committee(s) & $\square$ & • & - & - & - \\
\hline Assessors & & & & & \\
\hline External Assessors & o & - & - & - & - \\
\hline Full time assessors & - & - & - & - & - \\
\hline $\begin{array}{l}\text { Legal provision to publish list of approved } \\
\text { products }\end{array}$ & $\bullet$ & $\bullet$ & $\bullet$ & $\bullet$ & $\bullet$ \\
\hline Recognition of other MRA decision & - & - & - & - & - \\
\hline Harmonization of registration & 0 & $\begin{array}{l}\text { EAC } \\
\text { SADC }\end{array}$ & EAC & SADC & $\mathrm{ICH}$ \\
\hline Fast track registration & - & - & - & - & - \\
\hline $\begin{array}{l}\text { Collect fee for application } \\
\text { Target time frame to assess (in Months) }\end{array}$ & - & - & - & - & - \\
\hline New medicines & & 6 & 12 & 24 & 7 \\
\hline Generic medicines & & 6 & 4.5 & 12 & 1 \\
\hline Fast track applications & & 6 & 1.5 & 6 & - \\
\hline Registration validity period (years) & 4 & 5 & 1 & 5 & 5 \\
\hline
\end{tabular}

S: Stringent MRA and recognized by WHO prequalification program; $\bullet$ : Yes, $\circ$ : No; $\square$ : Yes but not functional during the assessment; SADC: Southern African Development Communities; EAC: East African Community: ICH: International Conference on Harmonization

Article 20 of Regulation 299/2013 of Ethiopia grants special permit for importation of unregistered medicinal products for clinical trials, scientific investigations, personalized use of a patient, laboratory quality testing for the purpose of registration, disaster and emergency aids, diplomatic missions and treatment of diseases with no adequate attention. although very limited, EU also provides exceptions for medicinal products for clinical trials, emergency situation and compassionate use.

Similar to other MRAs, the market authorization process in Ethiopia includes manufacturing premise inspection for GMP compliance, assessment of product dossiers and laboratory testing, where applicable. The requirements for Ethiopian market authorization are: (1) the medicinal product has to be included in to national medicine list; (2) the manufacturing site has to be approved and certified for compliance with GMP either by EFMHACA or other recognized stringent regulatory authorities and (3) such GMP certified or waived manufacturers have to submit application for dossier evaluation and product quality assessment accompanied with application fee.

Licensing and inspection: Law should create mechanisms to ensure that relevant parties are licensed and inspected so that the community can have confidence in them (22). Proclamation $661 / 2009$ states that the involvement of any person or institution in the pharmaceutical sector without being authorized or licensed is legally prohibited. A breach of law to trade medicine without certificate of competence shall be punishable with imprisonment of 5-7 years and fine of 2,700-5,400 USD (15).

Medicines retail outlets and supply chain inspections are mandated to RRBs, while EFMHACA is responsible for manufacturers, importers and wholesales inspection and licensing unlike TFDA, NDA, MCC and EMA. Moreover, 
the EFMHACA proclamation does not include requirements for obtaining licenses, terms and conditions for suspending or revoking activity and product licenses. It does not define the norms, standards and specifications to be applied in assessing the quality, safety and efficacy of medicinal products. These points and other similar details were left to be stated in the directives and guidelines to be prepared by EFMHACA based on the proclamation.

A review of 2010-2012 performance and activity reports indicated that EFMHACA is striving to exercise the legal mandate through preparations and approvals of different directives, standards, guidelines, standard operating procedures and check lists. Accordingly, the authority has prepared 39 standards, 14 directives and various guidelines in the last three years since proclamation 661/2009 has been enacted.

Control of raw materials: Proper quality management of pharmaceutical raw materials and excipients during collection, import, export, transport, distribution, storage, processing and documentation is a base to obtain safe, efficacious and good quality pharmaceutical products. Therefore, the source, origin and suitability of the starting material should be clearly defined and controlled.

In all the assessed MRAs, the finished pharmaceutical product (FPP) manufacturers are responsible for the control of raw materials (active pharmaceutical ingredients (APIs) and excipients). For EU, all imported active substances must have been manufactured in compliance with standards of good manufacturing practices (GMP) at least equivalent to the GMP of the EU (23), whereas for Ethiopia, compliance with Pharmacopoeia specifications and GMP procedures is adequate.

Implementation of medicines regulation in Ethiopia: The implementation status of medicines regulatory system in Ethiopia was addressed. The results of both in-depth interview of key informants and institutionsbased cross-sectional survey were used to evaluate its implementation.

Key informants perspective: All the key informants agreed that Proclamation 661/2009 is comprehensive in addressing all the pharmaceutical regulatory activities to protect public health. However, they stressed that the important regulatory tools that enable implementation of the proclamation have to be put in action since the sole existence of the law does not ensure its implementation.

Government's political commitment: All the key informants believe that there is strong political commitment from the government to support the pharmaceutical sector in general and the regulatory system in particular. The Government has already denoted the regulatory system as one of the pillars in the health sector. It produced provisions of proclamation for regulation of the pharmaceutical sector, empowered the regulatory authority to hire staff and acquire resources, established procurement system to supply government health institutions with pharmaceuticals and planned to enhance local production in its growth and transformation plan (GTP). The GTP capacitates local manufacturers and attracts investors to the pharmaceutical sector. However, the informants emphasized that more should be done to establish a strong medicine regulatory mechanism. According to them, the physical existence of the law, unless supported with a proper organization, qualified human resource and adequate finances, is not a guarantee for effective medicines regulation.

Product smuggling: According to the key informants, pharmaceutical products smuggling is recently emerging in Ethiopia and much worsening in remote areas of the country due to weak customs control. Some even claimed that they had observed similar problems even in the central part of the country including Addis Ababa.

The key informants mentioned that legally imported products were also diverted to the private sector. Some added that the problem was not only smuggling, but also the condition in which such products were transported and stored. The smuggled products are usually transported using animals through deserts without any care for the storage conditions, which could cause further damage or degradation to these products.

The majority of the key informants believed that both professionals and non-professionals in the legal and illegal institutions were stakeholders and responsible for the problems. Although some importers and distributors may be involved, the primary destinations of such illegal products were 
retail outlets and unregulated markets from which they were dispensed to the end users. Some of the key informants claimed that clinics were providing diagnostic and pharmaceutical services together for which they were not licensed.

As per the key informants, the main factors contributing to the existence of illegal products in the market were weak regulatory enforcement $(64.5 \%)$, poor inter-agency cooperation between law enforcing bodies $(62.2 \%)$ and weak boarder control $(50 \%)$. Decentralization of the regulatory activities to lower-level administrations with weak control capabilities created regulatory gaps and contributed for smuggling or diversion of the pharmaceutical products in Ethiopia.

Harmonization with-in law enforcing agencies at various administrative levels: Efforts of cooperation have been undertaken between medicine regulatory bodies at federal, regional states and other law enforcing agencies according to the EFMHACA informants. However, there is no established system with clearly defined roles and responsibilities of parties involved including inter-agency standard operating procedures. The informants added that in particular there is weak cooperation between the authority and the prosecutors at court, and thus most illegal cases taken to court were not successful.

Cross-sectional survey: Data were collected from a total of 249 respondents using self-administered questionnaire with the response rate of $94.3 \%$. The majority of the institutions, $175(71.1 \%)$, were from the central part of the country, i.e. Addis Ababa and its surrounding. This was because the majority of the institutions were concentrated around the capital.

Awareness about medicine regulation in Ethiopia: Of the total 249 respondents, 197(79.1\%) were not staff of EFMHACA, of which only $83(42.1 \%)$ reported awareness about the current medicine legislation of Ethiopia. The majority, 67(80.7\%), of those who had awareness reported that the medicine legislation is comprehensive enough to cover important pharmaceutical regulatory activities to protect public health.

Resources for medicine regulation: The study participants were EFMHACA staff members. They revealed that there is significant shortage of qualified and skilled human resource for medicine regulation in Ethiopia. Low salary, lack of attractive career structure and incentives were reported to be the leading contributing factors to problems in hiring and retainining qualified and skilled personnel within the regulatory system. Regarding the financial resources, the study participants confirmed that there was no adequate financing to perform the routine regulatory activities. This was due to insufficient government funding and weak revenue generating system from services, even though EFMHACA is mandated to use the revenue it generates from service delivery.

Unauthorized medicines sources: Out of the total respondents, $102(41.0 \%)$ reported that there were institutions and/or individuals involved in pharmaceutical business without being authorized or licensed to provide such services. According to the study participants, these unauthorized/illegal institutions are involved in importat and distribution to the medicine retail outlets (pharmacies, drug shops, rural drug venders, clinics), and even dispensing directly to the users. The study revealed that there were unauthorized sources for pharmaceutical products in all the major commercial cities of the country; with the majority existing in the eastern part $(71.4 \%, 10$ of 14 ) followed by the northern region $(53.6 \%, 15$ of 28) of the country.

Illegal pharmaceutical products: Seventy0eight (31.3\%) respondents reported that illegal pharmaceutical products were circulating in the pharmaceutical market of the country in the last 12 months preceding the study. It was reported that illegal pharmaceutical products enter into the distribution channel either through legal or illegal ports. However, the majority of the respondents believed that these products enter through illegal entry routes as presented in Figure 2. 


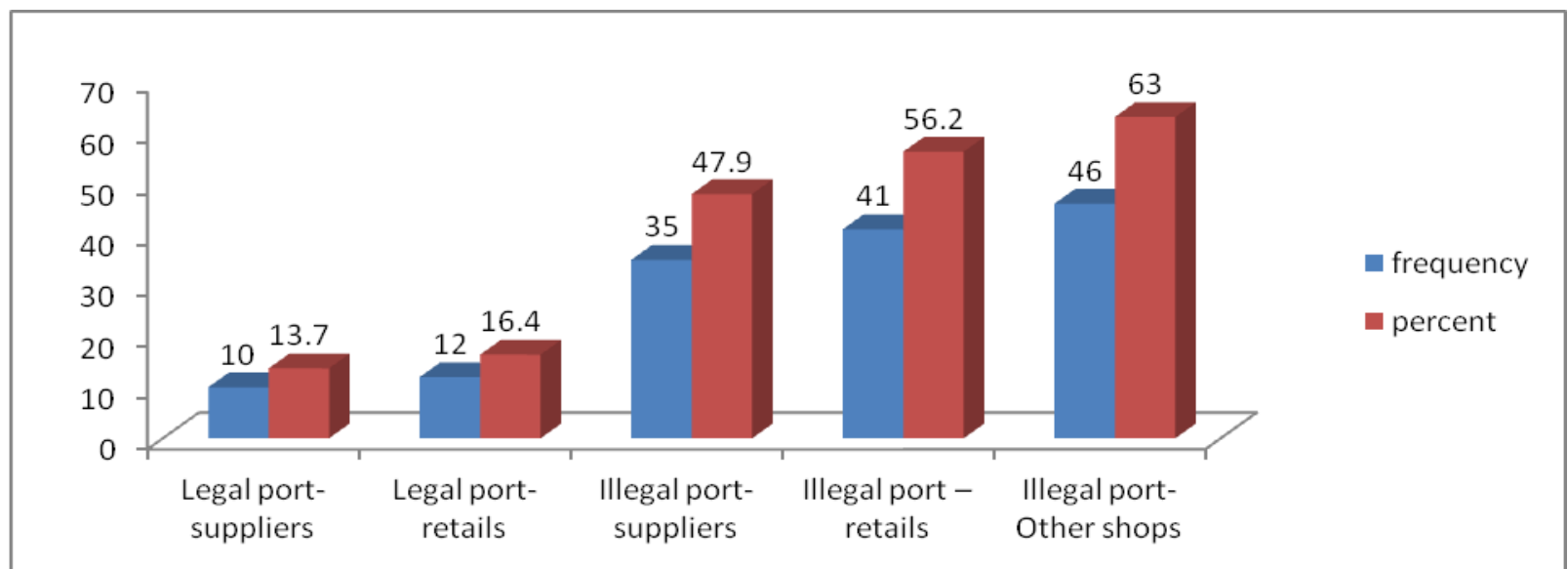

Figure 2: Reported entry route and destination of illegal products, Ethiopia, March 2013

The majority of the study participants (158, $63.5 \%$ ) reported that the main contributing factor for the presence of illegal sources was weak law enforcement. All the reported factors are presented in Figure 3. Anti-infective medicines (50\%) were the most frequently reported illegal pharmaceutical products (from which anti-malarial medicines cover more than a third) followed by hormonal drugs (insulin and oral anti diabetics, and sex hormone preparations) and contraceptives $(21 \%)$.

In a binary logistic regression analysis, variables such as, inadequate law enforcement/regulatory measures on illegal institutions, lack of informal market control, poor



control at entry ports, poor cooperation between FMHACA and regions, availability of illegal medicines, extra profit from illegal products and reporting illegal product were found to have significantly association $(\mathrm{p}<0.05$ at $95 \% \mathrm{CI}$ ) with the existence of illegal institutions in the pharmaceutical sector of the country (Table 5). From the multivariate logistic regression analysis performed on these variables, it was found that inadequate regulatory measures (enforcement), lack of informal market control, availability of illegal pharmaceutical products and location (site) of the country from the entry ports remained significantly associated with the existence of illegal institutions. 
Table 5: Selected factors on existence of illegal pharmaceutical institutions and products, Ethiopia, March 2013.

\begin{tabular}{|c|c|c|c|c|}
\hline \multirow[t]{2}{*}{ Variables } & \multicolumn{2}{|c|}{$\begin{array}{l}\text { Existence of illegal } \\
\text { institutions }\end{array}$} & \multirow{2}{*}{$\begin{array}{l}\text { Crude } O R(95 \% C I) \\
\text { p-value }\end{array}$} & \multirow{2}{*}{$\begin{array}{l}\text { Adjusted OR }(95 \% C I) \\
p \text {-value }\end{array}$} \\
\hline & Yes & No & & \\
\hline \multicolumn{5}{|c|}{ Inadequate regulatory measures } \\
\hline Yes & $84(53.2 \%)$ & $74(46.8 \%)$ & $4.35(2.38,7.97) 0.000$ & $3.50(1.84,6.65) 0.000$ \\
\hline No & $18(20.5 \%)$ & $70(79.5 \%)$ & 1.00 & \\
\hline \multicolumn{5}{|l|}{ Port control } \\
\hline Yes & $42(34.1 \%)$ & $81(65.9 \%)$ & 1.00 & 1.00 \\
\hline No & $60(48.8 \%)$ & $63(51.2 \%)$ & $1.84(1.09,3.03) 0.023$ & $1.13(0.63,2.03) 0.689$ \\
\hline \multicolumn{5}{|c|}{ Lack of informal market control } \\
\hline Yes & $74(49.7 \%)$ & $75(50.3 \%)$ & $2.40(1.39,4.1) 0.002$ & $1.97(1.08,3.60) 0.027 *$ \\
\hline No & $28(28.9 \%)$ & $69(71.1 \%)$ & 1.00 & 1.00 \\
\hline \multicolumn{5}{|c|}{ Lack cooperation b/n FMHACA \& regions } \\
\hline Yes & $50(33.6 \%)$ & $99(66.4 \%)$ & 1.00 & 1.00 \\
\hline No & $52(53.6 \%)$ & $45(46.4 \%)$ & $2.29(1.35,3.87) 0.002$ & $1.56(1.00,3.40) 0.153$ \\
\hline \multicolumn{5}{|c|}{ Illegal product exist } \\
\hline Yes & $46(59 \%)$ & $32(41 \%)$ & $2.88(1.65,5.00) 0.000$ & $2.79(1.52,5.11) 0.001$ \\
\hline No & $56(33.3 \%)$ & $112(66.7 \%)$ & 1.00 & 1.00 \\
\hline \multicolumn{5}{|c|}{ Reporting illegal product } \\
\hline Yes & $20(60.4 \%)$ & $13(39.4 \%)$ & 1.00 & $1.38(0.53,3.74) 0.532$ \\
\hline No & $82(38.5 \%)$ & $131(61.5 \%)$ & $2.46(1.16,5.21) 0.019$ & \\
\hline \multicolumn{5}{|c|}{ Extra profit from illegal product } \\
\hline Yes & $50(49 \%)$ & $52(51 \%)$ & $1.68(1.00,2.82) 0.048$ & $1.04(0.57,1.90) 0.892$ \\
\hline No & $52(36.1 \%)$ & $92(63.9 \%)$ & 1.00 & 1.00 \\
\hline
\end{tabular}

Inadequate regulatory measures/enforcement on violations was found to be strong contributing factor for the existence of unauthorized sources. Illegal institutions or individuals are more than three times significantly likely to exist in the pharmaceutical market when regulatory measures/enforcements are inadequate than when such measures are adequate $(\mathrm{AOR}=3.5,95 \% \mathrm{CI}$ $=(1.84,6.65)$, at $\mathrm{p}<0.001)$. Similarly, illegal institution are two times more likely to exist in the pharmaceutical market when informal market is unregulated than when it is regulated $(\mathrm{AOR}=$ $1.97,95 \% \mathrm{CI}=(1.08,3.595$ at $\mathrm{p}<0.05)$. The illegal sources are three times significantly more likely to exist in the presence illegal pharmaceutical products circulating in the market $(\mathrm{AOR}=2.785,95 \% \mathrm{CI}$ for $\mathrm{OR}(1.52,5.11)$, at $\mathrm{p} \leq$ $0.001)$.

The majority of the respondents claimed that they did not usually report the presence of illegal pharmaceutical institutions $(53.9 \%, 55 / 102)$ and products $(59.0 \%, 46 / 78)$. Details on awareness and reporting practice of the respondents is presented in Table 6. The main reasons for not reporting the problems were lack of formal reporting system, fear of security problems from smugglers, absence of legal measures for previous reports and lack of awareness to whom to report. 
Table 6: Awareness and reporting practice of respondents on problems related to pharmaceutical products in the market, Ethiopia, March 2013

\begin{tabular}{|c|c|c|c|c|}
\hline \multirow{2}{*}{$\begin{array}{l}\text { Problems related to pharmaceutical product } \\
\text { Illegal institutions }\end{array}$} & \multicolumn{2}{|c|}{ Aware of problem } & \multicolumn{2}{|c|}{$\begin{array}{l}\text { Reported problem } \\
\text { Frequency }(\%) *\end{array}$} \\
\hline & Yes & $102(41.5 \%)$ & Yes & $47(46.1 \%)$ \\
\hline & No & $144(58.5 \%)$ & No & $55(53.9 \%)$ \\
\hline \multirow{4}{*}{ Illegal products } & Total & 246 & Total & 102 \\
\hline & Yes & $78(31.7 \%)$ & Yes & $32(41 \%)$ \\
\hline & No & $168(68.3 \%)$ & No & $46(59 \%)$ \\
\hline & Total & 246 & Total & 78 \\
\hline \multirow{3}{*}{ Safety problems } & Yes & $98(39.8 \%)$ & Yes & $32(32.65 \%)$ \\
\hline & No & $148(60.2 \%)$ & No & $66(67.35 \%)$ \\
\hline & Total & 246 & Total & 98 \\
\hline \multirow[t]{3}{*}{ Drug abusers } & Yes & $38(17 \%)$ & Yes & $13(34.2 \%)$ \\
\hline & No & $186(83 \%)$ & No & $25(65.8 \%)$ \\
\hline & Total & 224 & Total & 38 \\
\hline \multirow{3}{*}{$\begin{array}{l}\text { Misleading/in-accurate } \\
\text { medicine promotion materials }\end{array}$} & Yes & $43(17.5 \%)$ & Yes & $18(41.9 \%)$ \\
\hline & No & $203(82.5 \%)$ & No & $25(58.1 \%)$ \\
\hline & Total & 246 & Total & 43 \\
\hline
\end{tabular}

*Percentage calculated of total aware or 'yes' at each point not of total respondents which is 246

\section{DISCUSSION}

An effective national pharmaceutical law is a primary means of ensuring that pharmaceutical policy goals are achieved with the unique character of pharmaceutical products, personnel and facilities is preserved. Therefore, when assessing the pharmaceutical regulatory system in Ethiopia from the legislation point of view, in terms of its purpose and content, evaluation of the framework based on WHO-standards and comparative review with other countries (Table 3) showned that the medicine legislation in Ethiopia provides basic legal framework and covers all products for which medicinal claims are made, as well as related pharmaceutical activities, in both the public and private sectors. In line with this, the cross-sectional study revealed that the legislation is comprehensive enough to cover all pharmaceutical regulatory activities important to protect public health.

Considering the significant public health implications of veterinary medicines in human health, the legislation in Ethiopia does not have provisions for the control of veterinary medicines in contrast to all other countries with which the comparative review was conducted. However, Ethiopia has a separate authority called veterinary drugs and animal feed administration and control authority established by Proclamation No. $728 / 2011$ to regulate the proper production, distribution and use of veterinary drugs to ensure safety, efficacy and quality of the products and to enhance the productivity and health of the livestock population. In fact, there should be at least exchange of information between this authority and EFMHACA with regard to full regulation of products, premises and practicing personnel.

The Ethiopian legislation mandated EFMHACA to prepare and approve or submit to appropriate organ for approval of regulatory standards and specifications to be applied in assessing the quality, safety and efficacy of medicinal products, and upon approval, to ensure the implementation. Accordingly, a number of guidelines including guidelines for human medicine evaluation, registration, and premises licensing and inspection have been prepared by EFMHACA got approval. However, the problem with such mandate is that guidelines approved by the regulatory authority are only administrative tools rather than statutory instrument in the court unless approved by the Council of Ministers, which in turn has an influence on enforcement of the law. Moreover, there were no reports found on joint operations between EFMHACA and other law enforcing 
agencies such as police and custom authority and this could be taken as additional evidence for lack of inter-agency cooperation in Ethiopia, which are very critical for effective medicine regulation $(5$, 8). Such operational cooperation was reported in other African countries and the experience in Uganda revealed a success story. A number of unregistered drug outlets were uncovered, and many counterfeit products were identified during joint operations between law enforcing agencies (MRA, customs, and police) in 2007-2011 in Uganda (24). The other major finding was that the responsibilities for pharmaceutical regulation in Ethiopia are distributed horizontally between two ministries and vertically between federal and regional state governments. Such fragmented systems among agencies could lead to overlap of responsibilities and regulatory ineffectiveness $(24,25)$ resulting in wastage of resources in the already poor-economy (26).

Literatures recommend harmonized optimal drug registration approach for resource-limited settings, which should reliably evaluate safety, efficacy and quality of drugs for use (27-29). However, Proclamation 661/2009 of Ethiopia does not have any article on regulatory harmonization with respect to market authorization unlike that of Tanzania, Uganda, South Africa and EU. However, currently Ethiopia is working towards possible harmonization among the IGAD member states on policy framework and regulatory system for pharmaceuticals and medical products quality assurance.

Although medicine legislation in Ethiopia prohibits the involvement in medicine trade without being licensed and sales by licensed importer and wholesaler to person or institution without certificate of competence, there exist institutions and/or individuals involved in pharmaceutical business without being certified to provide such services. Illegal transits and distributions are usually secret for regulatory inspections by customs or medicine regulatory bodies (30), and their existence could not only indicate inefficiencies in regulating the sector but also the presence of either unauthorized sources of medicine to the country or pharmaceuticals diversions. Therefore, it is reasonable to assume that these unlicensed institutions were the destinations for smuggled or diverted pharmaceutical products. This is in line with the reports of the study participants that such illegal institution or individuals are in an informal market for medicines, and a similar finding reported the existence of non-conventional markets for pharmaceutical products in Ethiopia (31), which could lead to the high prevalence of poor quality medicines.

The study participants reported that illegal medicines included both registered and unregistered products of which anti-infective medicines take the major share. Among medicines imported illegally, it is obvious that some were counterfeits and/or substandard. A national quality survey study conducted in Ethiopia reported a significant proportion of poor quality albendazole, mebendazole and tinidazole tablets on the Ethiopian market from which $29 \%$ was substandard (32).

This study reported diversion of medicines. Another study conducted on assessment of antimalarial diversion in 11 African cities including Addis Ababa showed that 6.5\% (58 of 894) samples of anti-malarial medicines collected from market were found to be diverted across at least one national border as determined by visual inspection (33). Diversion of medicine primarily affects sustainable procurement systems because it exacerbates stock outs in public health sector exposing patients to extra costs and making criminals profitable from diversion.

Inadequate enforcement of law was found to be the leading contributing factor for the presence of illegal institutions and/or products. Similarly, literatures revealed that inadequate legislation and weak or insufficient law enforcement along with resource constraints to to effectively implementing the law are among the regulatory factors that have contributed to the illegal circulation of medicines in many countries (34). Experiences in Australia, Canada and the United States have shown that adequate legislation and its enforcement result in fewer poor-quality medicines and greater public confidence in the quality of the medicines (30). Although the evidence for the feasibility of strict regulatory enforcements is very limited in low income countries, such interventions to improve regulatory compliance was reported to have impact on illegal sources in Vietnam and Lao Peoples Democratic Republic (35).

The strength of this study is that it included the strict EU regulatory framework and that of 
three African MRAs to evaluate the legal basis of Ethiopian pharmaceutical regulation. Moreover, it tried to address both the regulator and the regulated firms and professionals in the pharmaceutical sector. The other strength was the geographic coverage of the study, which was wider and encompassed the major trade cities and parts of the country.

Most archival data are collected for nonscientific reasons and thus often do not suit the purpose of the researcher. Moreover, pharmaceutical sector regulation is so sensitive and obtaining reliable and genuine data could be difficult.

From legislation point of view, it can be concluded that medicines regulation as a system in place in Ethiopia has potential capacity to develop in comparison with EU; and the three African countries like South Africa, which was reported by WHO in 2006 to have fully functional MRA. However, this study revealed that unauthorized/illegal medicine sources exist in the sector due to some in-efficiencies in the implementation of this regulatory system into the real practice. For instance, resource constraints as a basic factor along with other reported factors such as lack of informal market regulation, weak enforcement of the law and availability of illegal products are regulatory factors. Less reporting practice of illegal activities by professionals in the sector was also another important factor associated with the existence of illegal institutions in the pharmaceutical market.

The majority of medicines reported as illegally imported were anti-infective medicines including anti-malarial and other antibiotics. These reported products included both registered and unregistered products. Unregistered products do not only escape the necessary government tax, but they are also medicines for which quality, safety and efficacy are not ensured. Hence, they could be counterfeit, substandard and/or degraded products because of their transportation and storage conditions to hide from customs and regulatory authority.

Proclamation 661/2009 should be amended to include critical legislative gaps like harmonization. Product classification should be revised so that a strong autonomous regulatory system should take place. RRBs should have mechanisms of cooperating with EFMHACA.
EFMHACA should improve awareness about the current legal provision for medicine regulation. Moreover, detail national assessment of pharmaceutical malpractices and poor quality medicines should be conducted.

\section{ACKNOWLEDGEMENTS}

The authors acknowledge the support from the Infectious Diseases and Epidemiology Project within Institutional University Cooperation Programme (Jimma University) of VLIR and EFMHACA. The study was partly financed by Jimma University.

\section{REFERENCES}

1. World Health Organization. The safety of medicines in public health programs: Pharmacovigilance an essential tool. Geneva, Switzerland; 2006.

2. Anello E. A Framework for Good Governance in the Public Pharmaceutical Sector. Working draft for field testing and revision. Geneva, World Health Organization; 2008.

3. Cohen-Kohler JC, Baghdadi G. The world medicines situation 2011: Good Governance for the Pharmaceutical Sector. Geneva, World Health Organization; 2011.

4. Tobin JJ, Walsh G. Medical products regulatory affairs: Pharmaceuticals, Diagnostics, Medical Devices. Wiley- Blackwell, Weinheim; 2008.

5. Ratanwijitrasin S, Wondemagegnehu E. Effective drug regulation: A multi-country study. Geneva, World Health Organization; 2002.

6. World Health Organization. Substandard and counterfeit medicines. WHO Factsheet No 275, Geneva, Switzerland; 2003.

7. Gray A. Access to Medicines and Drug Regulation in Developing Countries: a Resource Guide. London: DFID Health Systems Resource centre; 2004.

8. World Health Organization. Effective medicines regulation: ensuring safety, efficacy and quality. Geneva, Switzerland; 2003.

9. Rago L, Santoso B. Drugs Benefits and Risks: International Textbook of Clinical Pharmacology. In: van Boxtel CJ, Santoso B, Edwards IR, editors. Uppsala: IOS press and Uppsala Monitoring center; 2008. Chapter 6, Medicine regulation: History, Present and Future; p. 65-77. 
10. World Health Organization. Assessment of medicines regulatory systems in sub-Saharan African countries. Geneva, Switzerland; 2010.

11. Transitional Government of Ethiopia. National drug policy of the Transitional Government of Ethiopia. Addis Ababa, Ethiopia; 1993.

12. Federal Democratic Republic of Ethiopia. Drug Administration and Control Proclamation 176/1999. Federal Negarit Gazette 1999; 5: 1105.

13. Federal Democratic Republic of Ethiopia. Food Medicine and Health care Administration and control Proclamation 661/2009. Federal Negarit Gazette, 2010; 16: 5157-91.

14. Food Medicine and Healthcare Administration and Control Authority. List of pharmaceuticals and related substances manufacturing establishments. Addis Ababa, Ethiopia; 2013.

15. Federal Democratic Republic of Ethiopia. Business Process Re-engineering: Health and health related Services and Products quality regulation Core process, Ministry of Health, Addis Ababa; Ethiopia; 2009.

16. Food, Medicine and Health care Administration and control Authority of Ethiopia, Strategies for Marketing Authorization of pharmaceuticals. Addis Ababa; Ethiopia; 2012

17. Ashigbie PG. Pharmaceutical regulation: A twelve country study: A Pharmaceutical Assessment Management and Policy (PAMP) practicum report; Boston University School of Public Health; 2011.

18. Abraham J, Lewis G. Regulating medicines in Europe: competition, expertise and public health. Routledge, London; 2000.

19. Curry LA, Nembhard IM, Bradley EH. Qualitative and Mixed Methods Provide Unique Contributions to Outcomes Research. Circulation, 2009; 119:1442-1452.

20. World Health Organization. Practical guide for conducting review based on WHO Data collection tool for the review of drug regulatory system, Module 3: National regulatory authority. Geneva; Switzerland; 2008.

21. Dicko M, Mihigo R, Onyeze A, Kandolo P, Nshimirimana D. Strengthening vaccine regulatory capacity in Africa: Status report. Geneva: World Health Organization; 2007.

22. Management Sciences for Health. MDS3: Managing access to medicines and health technologies. Arlington, VA; 2012.

23. International Conference on Harmonization. ICH Q7: Good Manufacturing Practice Guide for Active Pharmaceutical Ingredients. Geneva, Switzerland; 2000.

24. National Drug Authority of Uganda. Five years (2011-2016) Strategic plan document. Kampala, Uganda; 2011.

25. World Health Organization. Report of Situation of Counterfeit medicines: WHO regions for Africa and Eastern Mediterranean. Geneva; Switzerland; 2010.

26. Paul GA. Pharmaceutical regulation: A twelve country study, Boston University School of Public Health, Boston, USA; 2011.

27. Erhun WO, Babalola OO, Erhun MO. Drug regulation and control in Nigeria: The challenges of counterfeit drugs. J Health Popul Dev Ctries, 2001; 4: 23-34.

28. Deng R, Kaitin K. The regulation and approval of new drugs in China. Drug Inf J, 2004; 37: 2939.

29. Moran M, Strub-Wourgaft N, Guzman J, Boulet $\mathrm{P}, \mathrm{Wu} \mathrm{L}$, Pecoul B. Registering new drugs for low-income countries: The African challenge. PLoS Med 2011; 8: e1000411.

30. Pfizer. Counterfeit pharmaceuticals: A serious threat to patient safety. NY, USA; 2007.

31. Mustafa T. Assessment of pharmacy professionals' perception and experience towards non-conventional drug market: A pilot study on private pharmaceutical wholesales in Addis Ababa. Addis Ababa University School of Pharmacy (Unpublished M.Sc. Thesis), Ethiopia; 2011.

32. Sultan Suleman, Gemechu Zeleke, Habtewold Deti, et al. Quality of medicines commonly used in the treatment of soil transmitted helminthes (STH) and giardia in Ethiopia: a nationwide survey. PLoS Negl Trop Dis 2014; 8: e3345.

33. Bate R, Hess K, Mooney L. Anti malarial diversion: Stock-outs and other public health problems. Res Rep Trop Med, 2010; 1:19-24.

34. United States Pharmacopoeia. Ensuring the Quality of Medicines in Resource-Limited Countries: An operational guide. The United States pharmacopoeia convention. Rockville, $\mathrm{Md} ; 2007$.

35. Stenson B, Syhakhang L, Lundborg CS, Eriksson B, Tomson G. Private pharmacy practice and regulation. A randomized trial in Lao P.D.R. Int J Technol Assess Health Care, 2001; 17(4):579-589 